\title{
Predictability and Diagnosis of Low Frequency Climate Processes in the Pacific
}

\author{
Award Number: DE-FG02-04ER63862 \\ Final Technical Report \\ Niklas Schneider \\ International Pacific Research Center and Department of Oceanography \\ University of Hawaii at Manoa \\ Honolulu, HI 96822 \\ June 2009
}

\section{Introduction}

Work executed under this grant was part of a collaboration with colleagues at Scripps Institution of Oceanography, 'Predictability and Diagnosis of Low-Frequency Climate Processes in the Pacific', (Project ID: 0010486, Award Register\#: ER63857) that was reported independently by Dr. Arthur Miller, SIO. Predicting the climate for the coming decades requires understanding both natural and anthropogenically forced climate variability. This variability is important because it has major societal impacts, for example by causing floods or droughts on land or altering fishery stocks in the ocean. Our primary goal was to identify the physical processes of climate variability and change, which is necessary for accurate predictions. The bulk of the work of this collaboration directly addressed the major scientific objective of the BER CCRD, which is "accurate prediction of future climate on decadal to centennial timescales." The University of Hawaii portion was focused on the diagnosis of processes that govern natural climate variability on interannual to decadal time scales in the Indo-Pacific region. Specifically, the work focused on dynamics of the Pacific Decadal Oscillation, oceanic adjustments and the coupled feedback in the western boundary current of the North and South Pacific, decadal dynamics of oceanic salinity, and tropical processes with emphasis on the Indonesian Throughflow.

\section{North Pacific Decadal Variability}

\subsection{The Pacific Decadal Oscillation}

Decadal variability is widely described by the Pacific Decadal Oscillation, the leading empirical orthogonal function of North Pacific sea surface temperature anomalies. Its variations are alternatively attributed to mid-latitude or tropical processes. In Schneider and Cornuelle (2005), we quantify the relative importance from forcing by these regions, and show that the PDO can be recovered from a reconstruction of North Pacific sea surface temperature anomalies based on a first-order autoregressive model and forcing by variability of the Aleutian low, El Niño-Southern Oscillation (ENSO), and oceanic zonal advection anomalies in the Kuroshio-Oyashio Extension. The latter results from oceanic Rossby waves that are excited by North Pacific Ekman pumping. The SST response patterns to these processes are not orthogonal, so that their superposition determines the spatial characteristics of the PDO. The importance of the different forcing processes is frequency dependent. At interannual time 
scales, forcing from ENSO and the Aleutian low determines the response in equal parts. At decadal time scales, zonal advection in the Kuroshio-Oyashio Extension, ENSO, and anomalies of the Aleutian Low each account for similar amounts of the PDO variance. These results support the hypothesis that the PDO is not a dynamical mode, but arises from the superposition of sea surface temperature fluctuations with different dynamical origins.

\subsection{Processes in the Kuroshio and Kuroshio Extension}

The ocean is involved in Pacific decadal variations therefore in two ways: by storage temperature anomalies in the surface mixed layer, and by changes of ocean circulation. The latter is of particular interest as it reflects the slow evolution of oceanic Rossby waves, and leads to pronounced concentration of variance at decadal and longer time scales a the western side of the basin. These ocean circulation anomalies interact with the surface heat budget in the western boundary currents, and contribute to decadal modes such as the PDO as discussed in Schneider and Cornuelle (2005).

The western boundary currents are highly energetic and nonlinear circulation features, and produce decadal variance through both remote forcing and internal dynamics. These processes are investigated in Taguchi et al. (2007) and Schneider et al. (2009). In Taguchi et al. (2007) low-frequency variability of the Kuroshio Extension (KE) is studied using observations and a multidecadal (1950-2003) hindcast by a high-resolution $\left(0.1^{\circ}\right)$, eddy-resolving, global ocean general circulation model for the Earth Simulator (OFES). In both the OFES hindcast and satellite altimeter observations, low-frequency sea surface height (SSH) variability in the North Pacific is high near the KE front. An empirical orthogonal function (EOF) analysis indicates that much of the SSH variability in the western North Pacific east of Japan is explained by two modes with meridional structures tightly trapped along the KE front. The first mode represents a southward shift and to a lesser degree, an acceleration of the KE jet associated with the 1976/77 shift in basin-scale winds. The second mode reflects quasi-decadal variations in the intensity of the KE jet. Both the spatial structure and time series of these modes derived from the hindcast are in close agreement with observations. A linear Rossby wave model forced by observed wind successfully reproduces the time series of the leading OFES modes but fails to explain why their meridional structure is concentrated on the KE front and why it is inconsistent with the broad scale of the wind forcing. Further analysis suggests that KE variability may be decomposed into broad- and frontal-scale components in the meridional direction-the former following the linear Rossby wave solution and the latter closely resembling ocean intrinsic modes derived from an OFES run forced by climatological winds. The following scenario is suggested for low-frequency KE variability: basin scale wind variability excites broad scale Rossby waves, which propagate westward, triggering intrinsic modes of the KE jet and reorganizing SSH variability in space.

Schneider et al. (2009) studies the internal processes generating variance at interannual to decadal time scales in the western boundary regions. This difficult and prolonged investigation targets one of the premier examples of low frequency, oceanic internal variability, the Kuroshio Large Meander. Among the western boundary currents, the Kuroshio is unique in that it occupies distinct, discreet paths and either separates from the coast at Shikoku, loops offshore and returns to the coast west of Izu Ridge in a state called 'large meander', or it stays close to the coast in 'non-large meander' paths. The time occupied by large- or non-large meander path range for years to decades, while the transition between these states can happen on time scales shorter than a year. We investigated Kuroshio path dynamics in 
a 54 year, near global, eddy resolving hindcast with the Ocean Model for the Earth Simulator. The model produces vigorous fluctuation of the Kuroshio path based on a relaxation oscillation, with an equivalent barotropic vertical structure, and interannual to decadal time scales. Starting from a straight path, a meander develops close to Izu ridge. This meander then slowly retrogrades and strengthens until the system become unstable via mixed baroclinic/barotropic instability, and resets to a straight path. Analysis of potential vorticity indicates that the path curvature results from all components of potential vorticity with a near-balance of large and opposite fluctuations of shear vorticity and layer thickness due to divergences of the ageostrophic flow. These are traced to the slow eddy-driven, advective buildup of low potential vorticity in the anticyclonic recirculation gyre. Differences of observed and simulated path evolution are attributed to an underestimation of lateral exchange processes in the model.

The atmospheric response to these ocean induced fluctuations of surface temperature in the western boundary currents have been a long standing and contentious topic. In Qiu et al. (2007) air-sea coupled variability is investigated by focusing on the observed sea surface temperature signals in the Kuroshio Extension (KE) region of $32^{\circ}-38^{\circ} \mathrm{N}$ and $142^{\circ} \mathrm{E}-180^{\circ}$. In this region, both the oceanic circulation variability and the heat exchange variability across the air-sea interface are the largest in the midlatitude North Pacific. Sea surface temperature variability in the KE region has a dominant time scale of $10 \mathrm{yr}$ and this decadal variation is caused largely by the regional, wind-induced sea surface height changes that represent the lateral migration and strengthening/weakening of the KE jet. The importance of the air-sea coupling in influencing KE jet is explored by dividing the large-scale wind forcing into those associated with the intrinsic atmospheric variability and those induced by the SST changes in the KE region. The latter signals are extracted from the NCEP-NCAR reanalysis data using the lagged correlation analysis. In the absence of the SST feedback, the intrinsic atmospheric forcing enhances the decadal and longer time-scale SST variance through oceanic advection but fails to capture the observed decadal spectral peak. When the SST feedback is present, a warm (cold) KE SST anomaly works to generate a positive (negative) wind stress curl in the eastern North Pacific basin, resulting in negative (positive) local sea surface height (SSH) anomalies through Ekman divergence (convergence). As these wind-forced SSH anomalies propagate into the KE region in the west, they shift the KE jet and alter the sign of the preexisting SST anomalies. Given the spatial pattern of the SST-induced wind stress curl forcing, the optimal coupling in the mid latitude North Pacific occurs at the period of $10 \mathrm{yr}$, slightly longer than the basin-crossing time of the baroclinic Rossby waves along the KE latitude.

\subsection{Decadal variations of oceanic salinity}

In the study of decadal variations of the Pacific Ocean circulation and temperature, the role of salinity and anomalous net atmospheric freshwater [evaporation minus precipitation minus river runoff (EmP)] has received scant attention even though ocean salinity anomalies are long lived and can be expected to have more variance at low frequencies than at high frequencies. This question was explored by a GCM experiments of the feedback of surface temperature to forced salinity anomalies, and by the analysis of unique observations of decadal variability of salinity of the coast of California.

To determine the magnitude of salinity and temperature anomalies and their generation processes, Huang et al. (2005) studies the response of the Pacific Ocean to idealized EmP anomalies in the Tropics and subtropics using an ocean general circulation model developed at the Massachusetts 
Institute of Technology. Simulations show that salinity anomalies generated by the anomalous EmP are spread throughout the Pacific basin by mean flow advection. This redistribution of salinity anomalies causes adjustments of basin-scale ocean currents, which further results in basin-scale temperature anomalies due to changes in heat advection caused by anomalous currents. The response of the Pacific Ocean to magnitudes and locations of anomalous EmP is linear. When forced with a positive EmP anomaly in the subtropical North (South) Pacific, a cooling occurs in the western North (South) Pacific, which extends to the tropical and South (North) Pacific, and a warming occurs in the eastern North (South) Pacific. When forced with a negative EmP anomaly in the tropical Pacific, a warming occurs in the tropical Pacific and western North and South Pacific and a cooling occurs in the eastern North Pacific near $30^{\circ} \mathrm{N}$ and the South Pacific near $30^{\circ} \mathrm{S}$. The temperature changes $\left(0.2^{\circ} \mathrm{C}\right)$ in the tropical Pacific are associated with changes in the South Equatorial Current. The temperature changes $\left(0.8^{\circ} \mathrm{C}\right)$ in the subtropical North and South Pacific are associated with changes in the subtropical gyres. The temperature anomalies propagate from the tropical Pacific to the subtropical North and South Pacific via equatorial divergent Ekman flows and poleward western boundary currents, and they propagate from the subtropical North and South Pacific to the western tropical Pacific via equatorwardpropagating coastal Kelvin waves and to the eastern tropical Pacific via eastward-propagating equatorial Kelvin waves. The time scale of temperature response is typically much longer than that of salinity response because of slow adjustment times of ocean circulations. These results imply that the slow response of ocean temperature due to anomalous EmP in the Tropics and subtropics may play an important role in the Pacific decadal variability.

Hydrographic observations southwestward of the Southern California Bight in the period 1937-99 show that temperature and salinity variations have very different interannual variability (Schneider et al. 2005). Temperature varies within and above the thermocline and is correlated with climate indices of El Niño, the Pacific Decadal Oscillation, and local upwelling. Salinity variability is largest in the surface layers of the offshore salinity minimum and is characterized by decadal-time-scale changes. The salinity anomalies are independent of temperature, of heave of the pycnocline, and of the climate indices. Calculations demonstrate that longshore anomalous geostrophic advection of the mean salinity gradient accumulates along the mean southward trajectory along the California Current and produces the observed salinity variations. In Schneider et al. (2005) we found that the flow anomalies of this advective process are independent of large-scale climate indices. However, in Di Lorenzo et al. (2008) we find a new pattern of climate change, the North Pacific Gyre Oscillation (NPGO) and show that its variability is significantly correlated with fluctuations of salinity, nutrients and chlorophyll observed in the California Current. Fluctuations in the NPGO are driven by regional and basin-scale variations in wind-driven upwelling and horizontal advection associated with the North Pacific Oscillation, the second EOF of North Pacific sea level pressure. Nutrient fluctuations drive concomitant changes in phytoplankton concentrations, and may force similar variability in higher trophic levels. The NPGO pattern extends beyond the North Pacific and is part of a global-scale mode of climate variability that is evident in global sea level trends and sea surface temperature. This line of research has lead to a flurry of current activity that explore the oceanic dynamics and interaction with the tropics of the NPGO. 
Predictability and Diagnosis of Low Frequency Climate Processes in the Pacific

DE-FG02-04ER63862

\section{South Pacific variability}

The North Pacific variability has a counterpart in the Southern hemisphere, that, however, has received much less attention. Yet, it is by comparison of the ocean basins that we will be able to explore the robustness of low-frequency climate dynamics. In Sasaki et al. (2008) sea level variability and related oceanic changes in the South Pacific from 1970 to 2003 are investigated using a hindcast simulation of an eddy-resolving Ocean general circulation model For the Earth Simulator (OFES) along with sea level data from tide-gauges since 1970 and satellite altimeter since 1992. The first empirical orthogonal function mode of Sea level Anomalies (SLAs) of OFES exhibits broad positive SLAs over the central and western South Pacific. The corresponding principal component indicates roughly stable high, low and high SLAs, separated by rapid sea level fall in the late 1970s and sea level rise in the late 1990s, consistent with tide-gauge and satellite observations. These decadal changes are accompanied by circulation changes of the subtropical gyre at 1000-m depth, and changes of upper-ocean zonal current and eddy activity around the Tasman Front. In general agreement with previous related studies, it is found that sea level variations in the Tasman Sea can be explained by propagation of long baroclinic Rossby waves forced by wind stress curl anomalies, if the impact of New Zealand is taken into account. The corresponding atmospheric variations are associated with decadal variability of the El Niño-Southern Oscillation (ENSO). Thus, decadal sea level variability in the western and central South Pacific in the past three and half decades and decadal ENSO variability are likely to be connected. The sea level rise in the 1990s, which attracted much attention in relation to the global warming, is likely associated with the decadal cooling in the tropical Pacific.

\section{Tropical dynamics: The Indonesian Throughflow}

The common element of decadal variability described above is forcing from the tropics and El Nino Southern Oscillation (ENSO). One of the major current features that may influence interannual to decadal variability is the Indonesian Throughflow with impacts on the Indian Ocean and interactions with El Nino. Potemra and Schneider (2007a) explore the relationship between three- to ten-year variability in Indian Ocean temperatures and Indonesian throughow (ITF) volume transport is examined using results from a 300-year integration of the NCAR PCM coupled model. Correlation and regression analyses are used with physical reasoning to estimate the relative contributions of changes in ITF volume transport and Indian Ocean surface atmospheric forcing in determining low-frequency temperature variations in the Indian Ocean. In the PCM, low-frequency variations in ITF transport are small, 2 Sv, and have a minimal impact on surface temperatures (SST). Most of the low-frequency variance in Indian Ocean temperature (rms > 0:5C) occurs in the upper thermocline (75 to $100 \mathrm{~m}$ ). These variations largely reflect concurrent atmospheric forcing; ITF induced temperature variability at this depth is limited to the outflow region between Java and Australia extending westward along a band between 10 and 15S.

The relationship of IITF transport to ENSO is investigated in Potemra and Schneider (2007b). Seasonal anomalies of ITF transport are found to be forced by anomalous local, alongshore (South Java) wind as well as by anomalous winds in the equatorial Pacific and Indian Oceans. Ocean stratification, set up by surface freshwater fluxes and the ITF, partitions the anomalous forcing onto two separate layers in the ITF region, a near surface layer (approximately the upper $100 \mathrm{~m}$ ) and a thermocline layer 
Predictability and Diagnosis of Low Frequency Climate Processes in the Pacific DE-FG02-04ER63862

(approximately 100-500 m). Interannual anomalies in alongshore South Java winds and equatorial Indian Ocean winds cause changes in upper ocean ITF transport, while divergent winds over the equatorial Pacific and Indian Oceans control thermocline layer transport anomalies. Interannual periods when the total depth-integrated transport is most weak occur when there are anomalous westerlies in the equatorial Pacific, anomalous easterlies in the equatorial Indian Ocean (resulting in reduced thermocline level transport), and anomalous westerlies along the coast of southern Java (causing reduced upper ocean transport). Such conditions are found when there are cold sea surface temperature anomalies in the Indonesian Seas as well as the equatorial Indian Ocean, and thus are not strictly related to ENSO variability. Interannual variations in the ITF therefore are controlled by interannual variability associated with ENSO as well as by interannual variability in the Indian Ocean.

\section{Publications citing DOE support:}

Di Lorenzo E., N. Schneider, K. M. Cobb, K. Chhak, P. J. S. Franks, A. J. Miller, J. C. McWilliams, S. J. Bograd, H. Arango, E. Curchister, T. M. Powell and P. Rivere, 2008: North Pacific Gyre Oscillation links ocean climate and ecosystem change. Geophys. Res. Lett., 35, L08607, doi:10.1029/2007GL032838. ${ }^{1}$

Huang, B., V. Mehta and N. Schneider, 2005: Oceanic response to idealized net atmospheric freshwater in the Pacific at the decadal time scale. J. Phys. Oceanogr., 35, 2467-2486.

Potemra, J. T., and N. Schneider, 2007a: Influence of low-frequency Indonesian Throughflow transport on temperatures in the Indian Ocean in a coupled model. J. Climate, 20, 1339--1352, doi:10.1175/JCLI4146.1.

Potemra, J. T., and N. Schneider, 2007b: Interannual variations in Indonesian throughflow transport. $J$. Geophys. Res., 112, C05035, doi:10.1029/2006JC003808

Qiu, B., N. Schneider and S. Chen, 2007: Coupled decadal variability in the North Pacific: An observationally-constrained idealized model. J. Climate, 20, 3602--3620.

Sasaki, Y. N., S. Minobe, N. Schneider, T. Kagimoto, M. Nonaka and H. Sasaki, 2008: Decadal sea level variability in the South Pacific in a global eddy-resolving ocean model hindcast. J. Phys. Oceanogr., 38, 1731-1747.

Schneider, N., and B. D. Cornuelle, 2005: The forcing of the Pacific Decadal Oscillation. J. Climate, 18, 4355-4373.

Schneider, N., E. Di Lorenzo and P. P. Niiler, 2005: Salinity variations in the Southern California Current. J. Phys. Oceanogr., 35, 1421-1436.

Schneider, N. B. Qiu and H. Sasaki, 2009: The Kuroshio Large Meander in a Global Eddy Resolving Ocean Hindcast. J. Phys. Oceanogr., submitted.

Taguchi, B., S.-P. Xie, N. Schneider, M. Nonaka, H. Sasaki and Y. Sasai, 2007: Decadal Variability of the Kuroshio Extension: Observations and an eddy-resolving model hindcast. J. Climate, 20, 2357-2377.

1 DOE support is acknowledged in the contribution, but, due to a misunderstanding with the lead author, project DEFG02-04ER63862 is not listed. All other publications acknowledge this project. 